\title{
(En)countering counterfeits in Bangkok: the urban spatial interlegalities of intellectual property law, enforcement and tolerance
}

\author{
DANIEL F ROBINSON* AND DUNCAN MCDUIE-RA ${ }^{+}$ \\ *School of Humanities and Languages, Arts and Social Sciences, Morven Brown Building, UNSW 2052, \\ Australia \\ E-mail: d.robinson@unsw.edu.au \\ ${ }^{\dagger}$ School of Social Sciences, Arts and Social Sciences, Morven Brown Building, UNSW 2052, Australia
}

This paper was accepted for publication in January 2017

\begin{abstract}
In a Bangkok mall a fibreglass policeman warning against intellectual property (IP) piracy stands just metres away from vendors selling fake DVDs; a scene indicative of incomplete and unsuccessful attempts by foreign governments (the US and EU in particular) and corporate actors at enrolment towards ever-higher IP standards - the 'IP ratchet' that Drahos (2004 Intellectual property and pharmaceutical markets: a nodal governance approach Temple Law Review $77401-$ 24) describes. But the scene also reflects cultural resistance at the local level. Both readings exemplify the range of historical, cultural, and politico-legal factors at play that can only be understood through engagement with vendors and consumers in the markets and malls of Bangkok. IP laws may achieve partial 'closure' but are regularly changing, contested, variably enforced, and subject to existing social norms such as the 'cult of imitation', cultures of legal informality, and a lack of social contract. We found that this lack of legal closure was most pronounced in the day-to-day operation of the Pratunam Market. Whilst other sites host regular crack-downs by police, the IP-specific DSI force, and the Thai courts, markets like Pratunam are mostly immune despite being a transnational trade node for the production and export of counterfeit garments with other developing countries, and a non-conforming node in the IP enforcement context. In the face of persistent efforts to transpose Euro-American IP laws in countries like Thailand, alternative and resistant nodes representing 'spaces of interlegalities' are likely to persevere because of the historical context, and the socio-cultural norms of these places.
\end{abstract}

KEY WORDS: Bangkok, counterfeiting, intellectual property rights, legal geography, Thailand, imitation, walking ethnography

\section{Introduction}

A significant body of literature has emerged in legal geography examining the mutual constitution of law, space and place as a 'dynamic, shifting, often contradictory, multi-point process' (Delaney 2015, 97). Places and their social and cultural identities are (re)produced by a myriad of social actions, including importantly, the exercising of legal power and authority. At the same time, local conditions may create forms of regulation that can be thought of in terms of 'legal localization' (Holder and Harrison 2003, 4; see also Bennett and Layard 2015, 408), which develop their own unique enforcement requirements or responses and, importantly for this article, contradictions and silences.

Delaney $(2015,98)$ highlights that: 'one distinctive feature of this [legal geography] scholarship is a fine- grained, detailed attention to the complex processes of legal constitutivity and a desire to understand the reciprocal or mutual constitutivity of the legal and the spatial'. In this article we focus on the interlegalities ${ }^{1}$ existing between state law and nonstate laws, informal laws, norms, regulations, and customs; the latter being the more perceptible versions of legality or illegality that are lived by people in place. As Blomley highlights:

The closure of law has ... come under concerted attack from a number of legal critics who insist that law be seen for what it is: not only deeply implicated in the messy and politicized contingencies of social life but actually constitutive of social and political relations. It is this 'opening' of law, then, that is central to the critical program.

Blomley (1994, 7-8) 
This project of 'opening law' within critical legal geography is about recognising that there are spatial and temporal reasons that laws come into being. For centuries laws have emerged 'bottom up' from public norms through common law, traditional laws and customary law (e.g. see Tobin 2014); in the dominant/ normative mode through parliamentary deliberations and statute making; and through supra-national agreements like international environmental laws, and multilateral or bilateral free trade agreements. But even in modern urban spaces - Bangkok in this case forms of legal pluralism emerge through informal regulatory controls, accepted social and cultural norms, limited social contract, and the iterative movement between tolerance and repression under the law and within different spaces.

There has been much political uncertainty in Thailand since the ousting of Prime Minister Thaksin Shinawatra in 2006: a succession of coups; the Red Shirt/Yellow Shirt protests, battles and politics; and the recent death of King Bhumibol Adulyadej (Cohen 2012; Fong 2013; Forsyth 2010; Pongsudhirak 2008). These events have impacted on political stability and lawmaking - most notably the re-drafting of the constitution and issues of rule of law (Draper and Kamnuansilpa 2016). As these political and legal changes introduce uncertainties into society, the ability of the state to enforce the rule of law is compromised. This is most pronounced in aspects of law with limited social contract, such as intellectual property (IP) laws. The fundamental tenet of social contract theory is that individuals within society arrive at a mutually beneficial agreement to be governed by a state authority if they accept the terms of the laws and enforcement - and their associated moral norms or theories of justice - as fairness (Ng 2009). Where laws achieve minimal social contract, enforcement will be incomplete and 'illegalities' may be tolerated, and this appears to be particularly the case with IP (see Andrews 2014).

In this article we highlight the ways in which interlegal social responses emerge and evolve in different spaces (markets and malls) in Bangkok. We explore the emergence and imposition of global approaches to IP laws in Thailand through the lens of counterfeit goods, with varied effects in the social and cultural lives of IP (Coombe 1998). Legal controls and enforcement - and their spatial and temporal absences - are central to our concerns about how both the vending of goods, and their production as 'real', 'fake', or somewhere in between, vary amidst urban space in Bangkok. The goods themselves vary widely, muddying the purported binary between genuine and counterfeit goods: high-quality counterfeits; overproduced licensed goods; legally sold faulty or surplus goods; second-hand goods; and joke counterfeits. The legal controls emerge from specific and deliberate international or trans-national actornetworks and nodes of governance (or regulation)
(Drahos and Braithwaite 2002; Sell 2003 2010). These are manifest in international laws and unilateral sanctions which target the Thai state and then, potentially, impact on the local population with punitive and educative forms of enrolment.

However, the response from the many actors in Bangkok is far from predictable. The exertion of power operates through what we argue is a kind of network geopolitics. Rather than a simplistic scale hierarchy - global laws and regimes impacting on the state, which governs and orders citizen behaviour - the Thai state and infra-state publics have had a complex and evolving response to external and corporate pressures. Indeed within Thailand, corporate actors play a key monitoring and enforcement role, and typically seek disciplinary and punitive enforcement of pirate or counterfeit goods. Local street vendors and wholesalers operate in a changing realm between tolerance and enforcement that simultaneously shapes the spaces and conditions through which they are able (or not) to produce and sell their goods. In doing so, vendors consider the risks involved, for which there is less likelihood of punishment for selling copied clothes than copied DVDs or software, for instance. To highlight this we first consider a range of sites and then focus on one in particular, Pratunam Market, which we deem to be an exemplar of the interplay between national IP laws - heavily influenced by international norms and pressures, and local cultures of production, consumption, and the idea of Bangkok itself as a site where IP violations are a component of place; of what makes Bangkok desirable. What is being sold and where it is being sold has a major bearing on enforcement of IP.

\section{Approaching inter-legal responses in Bangkok}

To gain a sense of the ways IP laws are enrolled in Thailand we conducted formal interviews with leading IP law firms, custodians of the Museum of Counterfeit Goods, and key individuals involved in the writing of Thai IP law. We also benefitted from the contacts and collaborations shared by one of the authors with the National Human Rights Commission from 2005, during a period where IP and biopiracy were high on the agenda (see Robinson 2010 2013). To gain a sense of how these IP laws function and dysfunction 'on the ground' we conducted a walking ethnography of malls, markets, and vendor spaces (permanent and temporary) throughout the city individually and together. We interviewed vendors and consumers (40 in total, 34 of whom were vendors, plus 6 consumers) about the places where they sell goods, and observed how they were regulated, and the extent of enforcement of IP.

Walking ethnography seeks to capture the flows of everyday life in and between different spaces. As 
Edensor argues, walking reveals rhythms that intersect, 'adding to the complex polyrhythmy of place' $(2010,69)$. A mobile sense of place can be produced (and identified) 'through longer immersion by the walking body across a more extended space' (Edensor 2010, 70). In their introduction to a collection on walking ethnography, Ingold and Vergunst $(2008,3)$ argue 'It is along the ground, and not in some ethereal realm of discursively constructed significance, over and above the material world, that lives are paced out in their mutual relations'. As Cheng $(2014,212)$ notes, the practice of walking itself is a 'mobile and embodied practice' and 'inherently a rhythmic experience and potentially offer[s] insights to the multiple splices of time-space narratives'. Thus walking brings relational moments of ethnographic practice to the fore in ways that are difficult to obtain using other forms of mobility.

During our walking ethnography we paid attention to where goods were being sold, what was being sold, the manner in which objects were sold (clandestine, open), and visual and audible accompaniments to these activities. We were able to grasp a sense of the way flows of movement through different parts of the city - flows continually in flux following the creation and destruction of new walkways (above and underground), transport routes and hubs, vehicle and pedestrian thoroughfares, competing sites and vendors, extortion attempts, pockets of gentrification and of urban decline shape and are shaped by the desire to buy and to sell goods, including counterfeit goods. We were also able to gauge the ways crackdowns on counterfeit goods shape these flows and, in turn, the urban landscape of Bangkok in small but not insignificant ways.

Utilising this approach we were able to identify initial spaces of interest, compare our perspectives with one another and with respondents, and then zero-in on specific sites demonstrating the most varied and visible manifestations of IP laws and local cultures of contention for repeat visits. As a result we focused most intensely on Chatuchak weekend market in Chatuchak district, Mah Boon Krong Center (MBK) in Wang Mai district, Pantip Plaza and Pratunam Market both in Ratchetewi district, and smaller markets in Dusit district, and around Victory Monument. These sites require attention at different times of the day and night given the regulations over hours and days for vending in much of the city, the varied flows of customers through these sites, and the unpredictability of crackdowns by law enforcement. Pratunam is the main focus of this article as will be explained further below.

Cheng stresses the importance of objects encountered and discovered during walking and their power to 'disrupt the rhythm of walking, their power to affect our spatial orientations, as well as capture our attentiveness to their weighty existence' (2014, 214). For us, most of the objects we encountered of significance were the infrastructure of vending (carts, stalls, stock, staff), the ways infrastructure of the city was utilised by vendors (walkways, sidewalks, stairs, empty and abandoned enclaves), the infrastructure and symbols of enforcement (fixed signage, pamphlets, fake police), and the goods being sold. The latter objects proved a crucial component of the research. Sourcing, discussing and purchasing potentially counterfeit goods allowed us to have conversations with vendors not simply as researchers but as customers ${ }^{2}$. We found this an effective way to engage vendors without significantly jeopardising daily trade. This approach also gave us expertise on counterfeit goods themselves; price, costs, manufacturing sites, perceptions of quality, and the market for different types of goods in different locations. We begin this article with a discussion of hybrid laws in Thailand and the culture of imitation. We then present our analysis of the spatial politics of IP regulation in Bangkok itself before focusing on Pratunam market as an alternative node in the production and consumption of counterfeit goods.

\section{Evolving hybrid Thai law}

Historically the predominant influences on Thai law were local custom and Buddhism; the subsequent absolutist and nationalist pursuit of Thai-ness which is also linked to national Buddhist reforms under Mongkut (Winichakul 1994; Phongpaichit and Baker 2002); and Chinese and maritime influences from the surrounding regions, kingdoms and traders (Huxley 1996). Present day Thailand has a 'continental' civil law system (since 1935), elements of British common law, and aspects of traditional laws like the Law of the Three Great Seals of 1805, used to govern the gradually amalgamated Kingdom of Siam (Winichakul 1994; Kraichitti 1967). These still influence the Thai legal system, though they have been pushed to the background behind Western norms and supra-national and trans-national influences from international laws and bilateral trade agreements.

Although all legal systems evolve, Thailand's rule of law and legal system is not as 'settled' as some systems. The private law system in Thailand had much of the Civil and Commercial Code imported through 'legal borrowing/transplantation' since the early twentieth century (Pongsapan 2014; Engel and Engel 2010, 38-9). Similarly, strict IP laws have been imposed through entry into the World Trade Organization (WTO) and through bilateral coercion (discussed below) which includes rapid changes to existing IP laws and the creation of new laws that seek to protect traditional medicines and traditional plant varieties. Although Thailand has 'imported laws', this has not been a straightforward process 
and there has been considerable resistance within civil society and the bureaucracy that has sought to protect traditional Thai medicines and local wild or farmers' plant varieties through sui generis laws (see Robinson 2010 2013).

This interplay between importing, assimilating and copying foreign influences (products, culture, legal and political systems) is critical to our thesis. Amongst the Thai public and the political elite there are populist/revisionist and traditionalist attitudes which have influenced the predominant policies and laws, which evolve alongside the acceptability of imitation and importation of foreign concepts, products and ideas within Thai popular culture. There have been regular public debates in Thailand about the 'cult of imitation' and political and legal interventions in defining 'Thai-ness' going back to the early twentieth century during the reign of King Rama VI. As Reynolds explains:

... the issue of imitation - 'copying foreign models' - is an old one in Thai cultural debates about whether foreign products, be they consumer products, political systems, health regulations, or even sexual identities, are suitable to be copied.

Reynolds (1998, 131)

This includes an 'official version' of Thai Culture: watthanatham, 'qualities which indicated and promoted social prosperity, orderliness, national unity and development, and morality of the people' (Cornwel-Smith 2000, 11) - a centralised vision of a state culture from the top down. Popular cultural responses to this incorporate and assimilate foreign ideas; the incremental result of decisions by diverse, ordinary people reinventing the moment. Within popular culture in Thailand, the regularity of emulation, importation of ideas, and adaptation of designs or trends, is readily observable. CornwelSmith $(2000,10)$ explains: 'the elite feel compelled to adopt the styles of developed countries, which in turn gets copied by the Thai masses' often with these 'imports' being adapted with local variations; manifest in the joke emblazoned on t-shirts for sale throughout Thailand: 'same, same but different'. As Thai studies scholar Niels Mulders explains, 'Eclectic borrowing, temporisation, adaptive skill, and pragmatism are the very flavour of the Thai cultural genius ... They trust in their own ways; meanwhile they are not shy to incorporate whatever is perceived as useful and attractive' (cited in CornwelSmith 2000, 11). There are significant socio-cultural and historical factors that explain the ongoing desire to copy, import, adapt, emulate and assimilate designs and trends. This has direct relevance to IP in ways rarely acknowledged by researchers.

The legal geographic dimension of this interplay between official policy and popular response can be found in the particular and dynamic responses found in Bangkok's malls, markets and street-vending places. In crackdowns on IP piracy there is evidence of both punitive shows of force (involving state and corporate actors) and diffuse actions to limit it clearly with limited impact. Part of our analysis in this article is to understand the urban spatial enactment of these strategies and the ways they vary in effect due to the interlegalities between state law, dominant social norms, and the way laws are lived.

To explain further, Thailand has been referred to as having a 'law avoidance' culture (Kidder 2002; Engel 2005). This does not mean that people recklessly disobey the law, rather several studies suggest that local people seek to resolve 'legal' issues through customary, informal or ritualistic means, or even 'leave it to karma' (Engel 2005; Engel and Engel 2010; Huxley 1996; Robinson 2013). Often this means dispute resolution through a village head or local strongman. As Vandergeest and Peluso note:

In recognition of the limited power of the police in everyday matters, the kamnan and headmen were empowered to settle most small disputes and assess small penalties such as fines. The kamnan was able to call out the coercive power of the police to support him, and he thus became a locally powerful person. Although the judicial system was also reformed, until recently few rural people used the courts, preferring instead local brokers, the village head and kamnan, or district officials of the Ministry of Interior.

Vandergeest and Peluso (1995, 400)

Certainly the legal system is used for serious issues, particularly in Bangkok, but there are also various ways to resolve issues and disputes that do not involve the same level of 'escalation' and thus can save face for the parties involved. These mechanisms - like having security intimidate, move on or fine a vendor - might also be simpler, quicker and have other advantages (income). This produces interesting dynamics in the geopolitics of IP regulation, especially when it comes to the unilateral and bilateral pressures exerted from the US and European Union and the ways these are manifest in national laws and local cultures of navigating the law.

\section{The spatial politics of IPR regulation}

Intellectual property rights (IPRs) - the laws that mark, signify and enclose for private use innovations, signs and creative works as intellectual property - are a relatively recent concern for Thailand. Thailand has only had a Patents Act since the 1970s, Trademarks since 1991 and a Copyright Act from the 1930s. Limited domestic 
use of patents (more use of petty patents) highlights that IPRs are not necessarily a high priority for Thailand or many other developing or middle income countries ${ }^{3}$. Lall (2003) describes Thailand as a country with low technological activity based on a number of empirical indices. She indicates that:

These countries are likely to have both significant costs and potential long-term benefits from stricter patents, depending on the level of domestic technological capabilities and their reliance on formal technology inflows. Those that are building their innovation systems on the basis of local firms copying foreign technology and importing technologies at arm's length would gain less than those with a strong trans-national corporation presence.

Lall $(2003,14)$

Countries like Thailand are often persuaded and enrolled to implement IPRs, to induce foreign direct investment and trans-national corporate presence, even if this does not align well with historical and current innovation patterns dominated by imitation, design and incremental innovation.

At the national level Thailand is under pressure to enforce IPRs more strictly - particularly copyrights and trademarks - since the establishment of the Trade-Related Aspects of Intellectual Property Rights (TRIPS) in 1994. Prior to Thailand's ascension to the WTO in 1995, unilateral pressure to adhere to IPRs was applied through the US Trade Representative 'Special 301 Watch list'; a pressure that persists to the present (see Froman/USTR 2015).

Gradual coercion towards higher IP standards can be witnessed in Thailand ${ }^{4}$, reflecting what Drahos (2004) calls the global IP 'ratchet' effect, whereby corporations in the US and the EU have enrolled their government's trade negotiation arms towards a spiral of ever-higher protectionism. Initially they used bilateralism (free trade agreements) to coerce countries into compliance to achieve multilateral laws like TRIPS. Then with minimum standards of TRIPS enforced by a dispute settlement mechanism in the WTO, these actors continue to 'ratchet up' to seek and achieve higher protection standards through bilateral and regional agreements (Drahos 2004; Sell 2011). Drahos (2004) provides an explanation of 'nodal governance' in global IP laws and enforcement, with the nodal coordination of an international enforcement pyramid or network offering non-state actors (corporations and their affiliate lobby groups) the possibility of securing states' compliance with emerging global standards of IPRs. This actor-network functions through the enrolment of other actors towards compliance, typically through incentives, persuasion and coercion (Braithwaite and Drahos 2000).
While Thailand has made national gestures such as the creation of a specialised Intellectual Property and International Trade Court (Morgan 1999), the US Trade Representative notes that:

IPR enforcement does not seem to be a top priority for Thai law enforcement and poor coordination among government entities has seen limited improvement despite the launch of the National IPR Center of Enforcement in 2013.

Froman/USTR (2015)

Thailand was also excluded from the recently signed Trans-Pacific Partnership Agreement, suggesting further unease in diplomatic relations with the US and other key trading partners (interview with IP lawyers, 31 August 2015). The desire, both foreign and national, for improved enforcement of IPRs in Thailand has not been matched with coordinated action - there is a rupture in patterns of network enrolment.

\section{Local insights from markets and malls}

The tensions and contradictions that emerged in our analysis of IP law and enforcement in specific places in Bangkok is indicative of incomplete and unsuccessful attempts at enrolment. We argue this is not merely because of opportunistic resistance though this is a factor, but because of a range of historical, cultural, and politico-legal factors that can only be understood through engagement with vendors and consumers in the markets, malls and vendor places of Bangkok.

These pressures have meant that those producing and selling - and to some extent buying counterfeit goods are coming under increased pressure and surveillance by the police and specialist enforcement units including the IP-specific Department of Special Investigations (DSI) and the Teh Sah Kit (municipal police). Laws and regulations are adhered to in many instances, but are also ignored, challenged, and negotiated, primarily through bribes. Spaces where vending is permitted change rapidly as the city itself is shaped and reshaped through infusions of public and private capital and building booms and busts (Maneepong and Walsh 2013; Vorng 2011; Yasmeen and Nirathron 2014). However, this does not always involve the targeting of IPR violations. We found that IPR violations could be used as a punitive tool and threat, and for increasing the severity of punishments on nuisance vendors, noted specifically in interviews in Chatuchak (30 August 2015) and near Victory Monument (30 August 2015). As one vendor explained while looking side to side for police 'I'm not supposed to sell here. I have to keep a look out and pack up quickly, but business is $\mathrm{OK}^{\prime}$, 
suggesting it was worth the risk selling his handbags on a mat on the pavement near a bus station in central Bangkok (interview, Victory Monument, 30 August 2015). Enforcement - or the threat of enforcement - of laws around counterfeit goods and IPR violations add another layer to existing regulations around what can be sold, by whom, and when (see Figure 1). Rather than a small fine, IPR prosecutions pose a threat of larger fines (or bribes) and jail and so they may be used to exacerbate spatial ordering. Even while street vendors are targeted, vending inside buildings such as Chatuchak Market, Pantip Plaza and MBK Center is legitimised, though not without signage warning about piracy, occasional encounters with authorities, and a system of payments and bribes (e.g. one vendor described monthly payments to police in MBK). A double standard exists, whereby the 'soft targets' of street vendors are often made an example of, while largerscale actors such as mall owners are able to operate with minimal intervention (interviews with vendors, Chatuchak Market, 30 August 2015; Banglamphu, 1 September 2015; Victory Monument, 30 August 2015). This was exemplified in an interview just metres away from where we spoke to the above illegal footpath-based handbag vendor - a woman was selling imitation toys, pencil cases and goods on the steps of a mall saying 'this is permitted and I'm not hassled as long as I pay 1500 baht [ \$42USD] per day for the spot on the steps to the mall' (interview, Victory Monument, 30 August 2015).

To complicate further, some IPR holders view counterfeiting - at least on some level - as promoting a brand or line prior to registration and protection in Thailand. From interviews with local IP

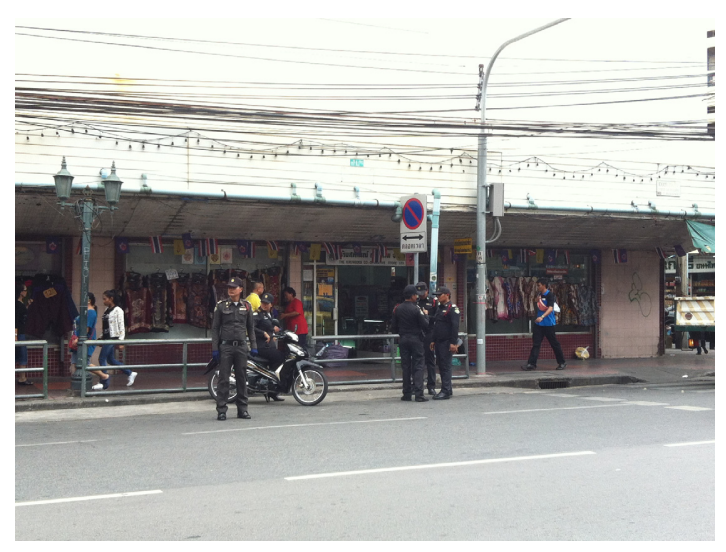

Figure 1 Teh Sah Kit patrolling Banglamphu area looking for vendors to fine and 'keeping order' on the footpaths and side streets

Source: Duncan McDuie-Ra, Banglamphu District Bangkok, $1 / 9 / 2015$. Used with permission of the author lawyers we heard that brands may even wait until counterfeits generate interest and then enter the market, after which they seek to register, and/or crack down and enforce their own IPRs (interviews with IP lawyers, 31 August 2015). Companies have also changed trademarked and copyrighted logos to identify and trap producers of counterfeit goods. For example, some clothing brands change their logo depiction slightly every two to three years to distinguish legal and illegal production by different factories - often including factories that have been licensed to produce the branded goods at one point. In other cases, counterfeit goods are the result of overproduction by manufacturers following the end of their contract that are then sold on to wholesalers or vendors. Other goods are seconds or rejects from manufacturers which, like the over-quota goods, exist in a liminal 'grey-zone' of IP law, making for dynamic interlegal spaces that pose challenges for local enforcement and the process of enrolment at the national level; exactly what constitutes an IPR violation or a counterfeit good is not always straightforward (interviews with IP lawyers, 31 August 2015 and vendors in multiple locations, August-September 2015) $)^{5}$. For example, in a local market in suburban Bangkok, a vendor explained that the 'Hello Kitty' and related clothes and children's accessories she sold were likely to be overproductions or seconds, and this seemed evident upon close inspection of the goods (interview 30 August 2015).

The DSI conducts showpiece raids on producers and wholesalers. These target electronics, CDs and DVDs, but may also target high-end bags, shoes and clothing - though not in all spaces as will be seen below. They also engage in visible public education campaigns aimed at consumers - both Thai and foreign. We did find examples of educational material written only in English (e.g. at Chatuchak and MBK), which suggests the performance of enforcement is important for generating a positive image of Thailand externally. These campaigns warn consumers against purchasing counterfeit goods and suggest surveillance of consumers and vendors. They take various forms ranging from warnings on the back of maps handed out to visitors to Chatuchak market (in English) to fibreglass policemen alongside a placard depicting a criminal peddling fake DVDs to a shocked consumer in Pantip Plaza (Figure 2). But these seem to have limited impact on vendor or consumer social contract as explained openly by one vendor in Chatuchak: 'we sell fakes but they are quality fakes, so people are happy to shop here' (interview, 30 August 2015). Some other vendors were more cautious in their explanations, but still were clearly willing to risk selling these goods and almost all vendors ultimately would explain whether their goods were real, fake or in between. 


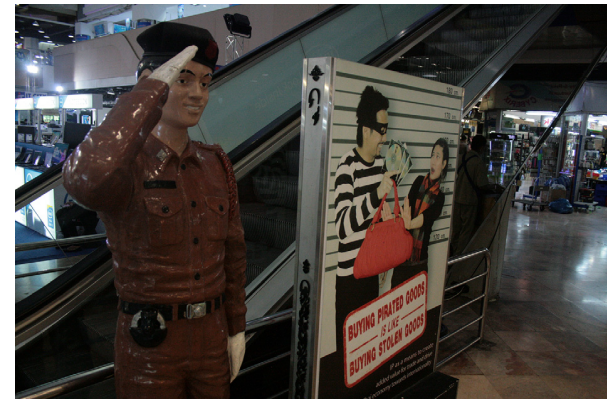

Figure 2 Fibreglass police officers and signage offering weak discouragement of IPR infringement

Source: Duncan McDuie-Ra, Pratunam District, Bangkok, $1 / 9 / 2015$. Used with permission of the author

Enforcement, even when uneven and uncoordinated, contrasts with the imagination of Bangkok as a city of transgressions for foreigners (Lafferty and Maher 2014; Maher and Lafferty 2014; Shimakawa 1995; Sugden 2007) and also for Thais (Wilson 2004). It is a city where the norms, rules and laws of elsewhere can be violated in big and small ways. The city has concentrations of urban space that cater to the desire for transgressions, from notorious sois offering sex shows and prostitution to markets and malls famed for counterfeit goods (Wilson 2004 78-87). The contrast between consumption in shining structures showcasing global luxury goods, commodity-specific locales where communities of merchants sell the same goods (or groups of goods), middle-class markets and malls supplying more mundane everyday consumption, and mobile peddlers and neighbourhood markets is made even more stark by their juxtaposition in seemingly small concentrations of urban space (King 2011). These malls and markets exist side by side in the centre and suburbs of Bangkok, highlighting the piecemeal attempts at - and genuine difficulty of - enforcement.

The social normalisation of consumption cultures can be seen as university-age students spill out of the expensive and tightly regulated malls of the Siam district to night markets across the road to shop for the much more affordable mixture of locally designed clothes or shoes; as well as to stalls selling fake handbags, clothes and accessories. That local vendors sell both in such close proximity to the main malls of Siam highlights the lack of social contract to respect IPRs for both vendors and consumers, local and foreign (interviews, Siam Square, 2-3 September 2015). This was notably just for clothes, with one electronics vendor in Siam Square noting 'Pantip Plaza is in decline because you can get software and stuff everywhere and download things illegally. But people are starting to want quality IT goods' (interview, Siam Square, 2 September 2015; with similar comments in interviews at Pantip, 1 September 2015). Further, nearby in MBK, the many small shops and stalls selling imitation clothes and shoes is evidence that the 'cult of imitation' is alive and well, but this space is 'largely for foreigners and young Thai men' (interview, MBK, 3 September 2015). As one vendor notes of his copied and humorous t-shirts, 'Thai people like to joke (len) with designs. People know they are fake. They like to buy them because they are funny' (interview, MBK, 3 September 2015). Imitated and adapted designs were also generally accepted in interview comments with vendors in other markets and malls (e.g. Chatuchak, Platinum Mall, Victory Monument) with casual comments like the clothes vendor in Chatuchak 'our designs and labels are very original, [but there is some appropriation, pointing to some shirts] - it's not really intellectual property' for shirts with Star Wars and other popular culture images integrated into designs (interview, Chatuchak, 30 August 2015).

These spatial interlegalities of regulation and enforcement are evident in other field sites such as near the Victory Monument and in Dusit. Entwined with the desire for transgression is the desire for consumption, a desire shared by Thais and foreigners alike. Certainly the brands and iconography protected by IPRs - typically from Japan, the US or Europe - can give products an appeal sought out by consumers as a cultural signifier of quality, wealth or status. Yet many of the goods sold in Bangkok are obvious fakes, and in some cases are humorous parodies of existing brands. Thus an ongoing process articulating Bangkok markets and malls as 'places of fakes' is reified as an attraction for tourists and local consumers.

\section{Pratunam Market and the shifting 'nodes' of imitation}

Pratunam Market is one of the largest wholesale garment markets in Thailand, and along with Bo Bae Market (also in Bangkok), is the primary garment hub. In recent decades, the Thai garment industry has been characterised by what Goto and Endo $(2014,1)$ refer to as 'a continuous search for low cost labour'. In response the industry has attempted to shift production from Bangkok to rural areas, border areas (where there is a supply of informal migrant labour), and other countries (China, Indonesia, Myanmar). However, these tactics have not diminished the importance of the greater Bangkok region for garment production, the base for $75 \%$ of the garment workers in Thailand (Goto and Endo 2014, 8).

Pratunam market is the exemplar of the way interlegal social responses emerge and evolve in Bangkok. Unlike Chatuchak and MBK Center, which are predominantly sites of consumption, Pratunam is a single space that acts as a node for both production and consumption. As a site of production it attracts not only tourists but wholesale traders who 
approach vendors in the market to make orders and discuss designs. We met vendors in Chatuchak who also sell wholesale goods, but these negotiations rarely take place on site and were far less common than in Pratunam. Pratunam fronts a number of streets, including the busy Petchaburi Road. The street-facing shops offer retail trade, and many deal in counterfeit goods, particularly t-shirts and handbags. Yet the core of the business is wholesale trade conducted in the warren of (air-conditioned) narrow laneways bisecting a series of undercover buildings. Goto and Endo conducted a survey among 50 wholesalers in Pratunam and found that $27 \%$ produce their stock in their own factories (usually small factories of fewer than 30 employees in suburban areas) and 23\% subcontract to 'small and micro[-scale] garment suppliers and home-based sub-contractors' $(2014,14)$. There is also a growing trend of subcontracting to garment manufactures in China, especially Guangzhou (17\%) (2014, 14). In our interviews it was noted that some of the brand name clothes are 'overproductions' contracted to manufacturers in Thailand for a period, but then production had shifted to another manufacturer or country, and the original manufacturer continued making the clothes using their existing templates. This makes it difficult to identify the IP infringed goods since they use an official template. Along with overproduced goods and emulated or adapted designs, are factory 'seconds' or flawed original goods (as also seen in MBK and Chatuchak market), and even brands that have been copied but are only just emerging on local markets and thus companies are not yet enforcing their IPRs (interviews, Pratunam Market, 1 September 2015; MBK, 2 September 2015; Chatuchak, 30 August 2015).

Pratunam draws thousands of vendors who lease space in the market itself, while also attracting mobile and itinerant vendors peddling goods in the market, at the entrances, and on the footbridges and pathways leading to it. The market has had a recent refurbishment and is clean and orderly; a change that has increased rents, something lamented by vendors. However, the point to note is that this is a formalised space; ordered, legitimate. This makes an interesting contrast between the physical space and the transactions that take place within, many of which are based on made-to-order counterfeits. The interior of Pratunam contains rows of small shops down long laneways. The shops in these back laneways are small, just enough space for a shop assistant or two to sit within three walls covered with garments - many of which are samples. What is striking is the openness in the negotiations over manufacturing counterfeit goods. During our time in Pratunam buyers would visit shops for quotes based on the styles being showcased. In many of the shops we visited the sample clothing on display also had a photograph or excerpt from a catalogue attached, demonstrating how closely the style could be mimicked; people can bring their designs from photos and magazines and we reproduce them' (interview, Pratunam, 1 September 2015). Some of these photographs or excerpts were from catalogues of major clothing brands (e.g. Esprit, Zara, Gucci) while some were unbranded approximations of current styles. Other stalls had surplus from custom orders, some of which bore little resemblance to known brands while some included pastiches of known logos. There were also orders where customers had requested purposeful variations to known brands - such as misspelt brand names probably to avoid legal difficulties in destination markets or with customs (interviews, Pratunam Market, 31 August- 1 September 2015).

Pratunam is a fascinating site to explore the relationships between IPRs and urban space as it suggests a permissive culture of violation of IPRs in the wholesale garment trade; especially at the middle and low end of the industry aimed primarily at the domestic market and traders from other parts of the developing world, a kind of 'low-end globalization' (see Mathews 2011). Counterfeit goods can be purchased and most significantly ordered and produced for distribution all over the world - mostly by single buyers. During our walking ethnography of the market, it was clear that the clientele in Pratunam includes Thais, but also foreign buyers from Africa and other parts of Asia, including a large number from South Asia. These are not snaphappy tourists as might be found in Chatujak or even MBK Centre, but serious wholesalers, often making deals with the assistance of translators and fixers who specialise in making deals in Pratunam.

We argue that in the IP context, the Pratunam Market appears to be an alternative or resistant node (see Drahos 2004), because it acts as a transnational garment hub that receives minimal coercion and enforcement from authorities. According to vendors, police harassment is minor and rarely extends beyond the usual modes of enforcement and protection; in other words it has little to do with the possibility of IPR violations. While garment factories associated with Pratunam vendors may be raided from time to time, the functioning of the market itself appears undisturbed. Indeed the visual trappings common in other spaces mentioned above, from fibreglass police to consumer warnings, are completely absent from Pratunam. Vendors complained more about high rents (in part caused by renovations), slow sales, and smaller orders, but not Teh Sa Kit or the DSI (interviews, 1 September 2015).

The reputation of Pratunam for garments has attracted a number of up-scale capital-intensive shopping malls in close proximity, including the Platinum Fashion Mall, and there are several hotels surrounding the market which receive general traffic but also traders in Bangkok specifically there to 
make deals at Pratunam. These 'spill-over' areas are interesting because they target tourists and young local consumers with local designer or 'boutique' goods that adapt a mixture of local, simple and imported branded designs. They are located near garment hubs; 'places of fakes', but are a mixture of locally designed, counterfeit, and adapted styles. A number of young Thai consumers interviewed indicated they shopped in these spill-over areas because they wanted affordable unique, designer and quality clothing (including counterfeit and noncounterfeit goods). For these local consumers, quality and design were prioritised in their social contract over an IP consideration, at least for clothes and related goods (interviews, Platinum Mall, Siam Square and Chatuchak Markets, 30 August-3 September 2015) ${ }^{6}$.

As a hub for the distribution and soliciting of garment manufacturing (not to mention export duties), the value of Pratunam to the city and to spill-over business appears to outweigh any benefits of crackdowns within the market itself. Made to order fakes, it seems, are a more legitimate form of counterfeiting, particularly when they are peddled and consumed as part of an enormous and firmly established urban space that targets a lower end of the market and does not infringe upon consumption at the higher end of the economy.

\section{Conclusions}

The tensions and contradictions that emerged in our analysis of IP law and enforcement in specific places in Bangkok are indicative of incomplete and unsuccessful attempts at enrolment towards ever higher IP standards. We argue this is not only because of opportunistic or economic forms of resistance, but also because of a range of historical, cultural and politico-legal factors that have meant that the legal system and its enforcement is a hybrid of many influences. The laws never quite achieve 'closure' but rather are regularly changing, contested, variably enforced, and subject to existing social norms, legal informality and legal pluralism. This is perhaps most pronounced in the day-to-day operation of the Pratunam Market. Whilst other notorious sites like the electronics mall Pantip Plaza have been the site of regular crack-downs triggered by non-state actors enrolling police, the DSI and the Thai courts, markets like Pratunam are a lower threat despite being a transnational trade node with other developing countries, and a non-conforming node in the IP enforcement context.

There are a few explanations for this. First, Pratunam operates as a market of both production and consumption. Original, imitated and counterfeit goods exist alongside one another and identifying firm IPR violations is difficult without specific expertise. Furthermore, original brand name clothes and related accessories may have been legally produced in Thailand for a period, and are 'overproduced' or continued illegally after the end of the contract using the same templates. The clothes and related accessories (shoes and handbags) can be produced illegally with copied labels in Thailand until there is sufficient market interest, and then the companies start enforcing their IPRs. In the case of software or computer hardware piracy, there is no market advantage for the companies in waiting to enforce, as the software or DVD copies are near identical at the point of sale (but often of lesser screen quality once the buyer gets it home); and poor quality imitation computer hardware risks impacting company reputation.

Second, there are evident complexities of social contract amongst Thai people and also for tourists with regards to clothes, shoes and handbags, as opposed to say computer hardware or even software where IP enforcement is more rigorous; at least symbolically. The market for counterfeit electronic goods appears to be shrinking; evident in nearby Pantip Plaza - the site of the fibreglass cop - which was half empty in mid-2015 and revived as an almost wholly IP-respecting space by mid-2016. In contrast, the garment industry is still a magnet for counterfeit goods traded all over the world. Interviews with vendors and consumers suggest this is partially a result of differing perceived social contracts for different goods. While it was commonly accepted that purchasing and selling fake branded t-shirts and clothes was worth the risk by consumers and vendors, consumers were less likely to accept the same risk for computer hardware. This element of social contract is also partly related to the ability to adapt and modify clothes designs and logos as a creative and sometimes even humorous activity, whereas copying DVDs, software and computer hardware has no creative element (interviews, Chatuchak, Siam Square and MBK, 30 August-3 September 2015). There is an awareness among local consumers that even counterfeit garments may be relatively high-quality factory seconds, overproduced originals, and generally have a high reputation regionally and globally whether counterfeit or not. Very cheap fake clothes are often obviously fake and often humorous ('lor len') and there is a perception amongst local people that this is tolerable imitation. In weighing the above considerations, producers and vendors have to consider the risks of being arrested or fined, but there has been a more protracted focus on DVD and software piracy and sales by US companies, the FBI and by their counterparts in Thailand than for clothes.

Third, popular culture in Thailand regularly imitates, imports, adapts and assimilates concepts and designs. This, as well as the above point, influences a vendor's social contract with the law - whether they accept it, think it is fair or just, or is worth the risk ignoring. In Pratunam or its spill-over areas, being creative or playful with brands or another's designs 
might actually be seen as something to be proud of, as opposed to the 'burning DVDs' idea of piracy. With an expanding middle class, local Thais noted that there are booming local designer fashion boutiques and shops in areas of central Bangkok around Siam Square or in Platinum Mall. But even within these there is evidence of the more 'playful' or even overt adaptations of foreign designs. There are limits to how original the design of items of clothing can be, and so inspiration is often drawn from trends that cross international and legal boundaries.

In the face of persistent efforts to transpose EuroAmerican IP laws in countries like Thailand, alternative and resistant nodes like Pratunam market will persevere until extreme pressure makes the practices of counterfeiting and imitation too risky. As we have explained, these resistances are because of the historical contexts and socio-cultural norms of these places, aside from economic and 'developmental' reasons that are the usual points of focus of research on counterfeit cultures.

\section{Acknowledgements}

We would like to acknowledge and thank the referees and Editor for their constructive and useful comments which have improved the paper.

\section{Notes}

1 'Interlegality is seen as a continuous process elucidating the interchange of legal perceptions between state law and nonstate law, i.e. a dynamic approach to legal pluralism' (Svensson 2005, 51); or as a multiplicity of legal orders and the relationships that exist between them at different scales (Santos 1995)

2 Some goods were deliberately purchased because they appeared real, but because of the context (e.g. location of sale, error or typo on the product) it was unclear if they were genuine or fake. These were then shown to IP lawyers to determine if they were genuine, before relinquishing the goods.

$3 \mathrm{Dr}$ Somkiat Tangkitvanich from the Thai Development Research Institute indicated that a staggeringly high proportion of 'innovation' patents - 94\% - belong to foreign companies or individuals and this has not changed much over time (Interview, 16 February 2006). However, Thai innovators are much more likely to utilise the utility model, designs or 'petty patent' system to register their more incremental innovations, with approximately $93 \%$ of utility model registrations currently being held by Thai nationals. Dr Somkiat indicates that there is a considerable 'disconnection' between the production sector and the inventor - inventions in Thailand are typically lower technology and 'indigenous', having local application, hence the preference for utility model protections (Interview, 16 February 2006). To put this into perspective, in the year following amendment of the Patent Act in 1989, only 32 Thai citizens patented their inventions, compared with 2412 foreigners (Buntoon Srethasirote, Bangkok Post, 9 February 2006). A 2007 study
(Kuanpoth 2007, 49-50) found only slight increases in domestic registrations for innovation patents.

4 This has been witnessed first hand by the author, Dr Robinson, who has worked as a research fellow and consultant advising the Thai government and several other countries on free trade agreements.

5 For example, one t-shirt was shown to the IP lawyers we met which appeared to be a genuine production of a major department store, but which had a typo in the print. The IP lawyers indicated it was probably what is known as a 'real fake' - a real product but incorrectly produced and so sold on by a third party either legally (with permission as a 'factory second') or illegally (interview with IP lawyers, 31 August 2015)

6 These same priorities were highlighted in the governmentbacked Thailand Culture and Design Centre 'What is Design Gallery' during our fieldwork, which illustrates 10 countries and 'how they have interpreted their cultural uniqueness into 20th century industrial design classics and explores the genius loci of industrial design in Thailand' (Thailand Culture and Design Centre signage, observed during fieldwork, 3 September 2015). The overwhelming impact of the gallery is to suggest that foreign designs dominated most of the twentieth century and that Thai design has only recently been catching up through a process of adaptation, emulation and creativity.

\section{References}

Andrews S J 2014 Modernity, law and the violence of piracy, property and the state in Fredriksson $\mathbf{M}$ and Arvanitakis J eds Piracy: leakages from modernity Litwin Books, Sacramento 97-116

Bennett L and Layard A 2015 Legal geography: becoming spatial detectives Geography Compass 9 406-22

Blomley N 1994 Law, space, and the geographies of power Guilford Press, New York

Braithwaite J and Drahos P 2000 Global business regulation Cambridge University Press, Cambridge

Cheng Y 2014 Telling stories of the city: Walking ethnography, affective materialities, and mobile encounters Space and Culture 17 211-23

Cohen E 2012 Contesting discourses of blood in the 'red shirts' protests in Bangkok Journal of Southeast Asian Studies 43 216-33

Coombe R J 1998 The cultural life of intellectual properties: authorship, appropriation and the law Duke University Press, Durham

Cornwel-Smith P 2005 Very Thai. Everyday popular culture River Books, Bangkok

Delaney D 2015 Legal geography I: Constitutivities, complexities, and contingencies Progress in Human Geography 39 96-102

Drahos P 2004 Intellectual property and pharmaceutical markets: a nodal governance approach Temple Law Review 77 401-24

Drahos P and Braithwaite J 2002 Information feudalism: who owns the knowledge economy? Earthscan, London

Draper J and Kamnuansilpa P 2016 Thailand hampered by its failure to enact the law Bangkok Post 31 October, 9

Edensor T 2010 Walking in rhythms: place, regulation, style and the flow of experience Visual Studies 25 69-79 
Engel D M 2005 Globalisation and the decline of legal consciousness: torts, ghosts, and Karma in Thailand Law and Social Inquiry 30 469-514

Engel D M and Engel J S 2010 Tort, custom, and karma. Globalisation and the decline of legal consciousness in Thailand Stanford Law Books, Stanford CA

Fong J 2013 Political vulnerabilities of a primate city: the May 2010. red shirts uprising in Bangkok, Thailand Journal of Asian and African Studies 48 332-47

Forsyth T 2010 Thailand's red shirt protests: popular movement or dangerous street theatre? Social Movement Studies 9 461-7

Froman M B G/USTR (United States Trade Representative) 2015 2015. Special 301 report USTR, Washington

Goto K and Endo T 2014 Upgrading, relocating, informalising? Local strategies in the era of globalisation: the Thai garment industry. Journal of Contemporary Asia 44 1-18

Holder J and Harrison C eds 2003 Law and geography Oxford University Press, Oxford

Huxley A 1996 Thai, Mon \& Burmese Dhammathats - who influenced whom? in Huxley A ed Thai law: Buddhist law White Orchid Press, Bangkok 81-132

Ingold T and Vergunst J L 2008 Ways of walking: ethnography and practice on foot Ashgate Publishing, Aldershot

Kidder R L 2002 Exploring legal culture in law-avoidance societies in Starr $\mathbf{J}$ and Goodall $\mathbf{M}$ eds Practicing ethnography in law Palgrave Macmillan, New York 87-107

King R 2011 Reading Bangkok NUS Press, Singapore

Kraichitti S 1967 The legal system in Thailand The Washburn Law Journal 7239

Kuanpoth J 2007 Harmonisation of TRIPS-Plus IPR policies and potential impacts on technological capability: a case study of the pharmaceutical industry in Thailand ICTSD-UNCTAD and IDRC, Geneva

Lafferty M and Maher K H 2014 The expat life with a Thai wife: Thailand as an imagined space of masculine transformation in Liamputtong $\mathbf{P}$ ed Contemporary socio-cultural and political perspectives in Thailand Springer, New York 311-27

Lall S 2003 Indicators of the relative importance of IPRS in developing countries International Centre for Trade and Sustainable Development (ICTSD), Geneva. (https://www.iprsonline.org/re sources/docs/Lall\%20-\%20Indicators\%20of\%20relative\%20impor tance \%20of\%20IPRs\%20in\%20DC\%20-\%20Blue\%203.pdf) Accessed 02 March 2017

Maher K H and Lafferty M 2014 White migrant masculinities in Thailand and the paradoxes of western privilege Social \& Cultural Geography 15 427-48

Maneepong C and Walsh J C 2013 A new generation of Bangkok street vendors: economic crisis as opportunity and threat Cities 34 37-43

Mathews G 2011 Chetto at the center of the world: Chungking mansions, Hong Kong University of Chicago Press, Chicago IL

Morgan A 1999 TRIPS to Thailand: the act for the establishment of and procedure for intellectual property and international trade court Fordham International Law Journal 23795

Ng A 2009 Social contract and authorship: allocating entitlements in the copyright system The Fordham Intellectual Property, Media \& Entertainment Law Journal 19 413-82

Phongpaichit P and Baker C J 2002 Thailand, economy and politics Oxford University Press, Oxford
Pongsapan M 2014 Thai law as a civil law system Center for Asian Legal Studies Workshop, National University of Singapore, 14 October 2014. (https://law.nus.edu.sg/pdfs/cals/ events/pongsapan_tlcls.pdf (Accessed 166 January 2017)

Pongsudhirak T 2008 Thailand since the coup Journal of Democracy 19 140-53

Reynolds C 1998 Globalization and cultural nationalism in modern Thailand in Kahn J S ed Southeast Asian identities: culture and the politics of representation in Indonesia, Malaysia, Singapore, and Thailand I B Taurus Publishers, New York 115-45

Robinson D 2010 Locating biopiracy: geographically and culturally situated knowledges Environment and Planning $A$ 42 38-56

Robinson D F 2013 Legal geographies of intellectual property, 'traditional' knowledge and biodiversity: experiencing conventions, laws, customary law, and Karma in Thailand Geographical Research 51 375-86

Santos B D-S 1995 Toward a new common sense: law, science and politics in the paradigmatic transition Routledge, New York

Sell S K 2003 Private power, public law: the globalization of intellectual property rights Cambridge University Press, Cambridge

Sell S K 2010 The global IP upward ratchet, anti-counterfeiting and piracy enforcement efforts: the state of play PIJIP Research Paper no. 15, American University Washington College of Law, Washington DC

Sell S K 2011 TRIPS was never enough. Vertical forum shifting, FTAs, ACTA, and TPP Journal of Intellectual Property Law 18 447-76

Shimakawa K 1995 Fake intimacy: locating national identity in Dennis O'Rourke's "the good woman of Bangkok" Discourse 17 126-50

Sugden J 2007 Inside the grafters' game: an ethnographic examination of football's underground economy Journal of Sport \& Social Issues 31 242-58

Svensson T G 2005 Interlegality, a process for strengthening indigenous peoples' autonomy: the case of the Sámi in Norway The Journal of Legal Pluralism and Unofficial Law 37 51-77

Tobin B 2014 Indigenous peoples, customary law and human rights - why living law matters Routledge, Oxon

Vandergeest P and Peluso N L 1995 Territorialization and state power in Thailand Theory and Society 24 385-426

Vorng S 2011 Bangkok's two centers: status, space, and consumption in a millennial Southeast Asian city City \& Society 23 66-85

Wilson A 2004 The intimate economies of Bangkok: tomboys, tycoons, and Avon ladies in the global city University of California Press, Berkeley CA

Winichakul T 1994 Siam mapped: a history of the geo-body of a nation University of Hawaii Press, Honolulu

Yasmeen G and Nirathron N 2014 Vending in public space: the case of Bangkok WIEGO Policy Brief (Urban Policies) No 16 May 2014. (http://wiego.org/sites/wiego.org/files/publications/f iles/Yasmeen-Vending-Public-Space-Bangkok-WIEGO-PB16. pdf) Accessed 15 December 2015 